\title{
UMA EXPERIENCIA COM CONSULTAS DE ENFERMAGEM PARA CRIANÇAS
}

\author{
Maria Jacyra de Campos Nogueira *
}

RBEn/08

NOGUEIRA, M.J.C. - Uma experiência com consultas de enfermagem para crianças. Rev. Bras. Enf.; DF, $30: 294-306,1977$.

\section{INTRODUÇAOO}

Este trabalho relata uma experiência realizada durante o ensino de campo (estágio) proporcionando aos alunos de Habilitação em Enfermagem de Saúde Pública, da Escola de Enfermagem da USP, pelos docentes da disciplina Enfermagem de Saúde Pública da referida escola.

Foram realizadas, experimentalmente, algumas consultas para crianças aparentemente sadias que frequentavam dois centros de saúde da Secretaria de Estado da Saúde do Governo do Estado de São Paulo. Esse grupo de crianças, só procurava a consulta médica quando a mãe as considerava doentes e não havia, em ambos os serviços, de rotina, um controle da sua saúde por meio de consultas médicas ou de enfermagem.

Primordialmente, as consultas de enfermagem tiveram as seguintes finalidades:
-- avaliar a validade desse tipo de assistência realizada por enfermeiras de saúde pública;

- proporcionar experiência aos alunos.

\section{METODOLOGIA}

Inicialmente as crianças escolhidas para esse estudo, deveriam pertencer à faixa etária de 0 a 6 anos. Posteriormente, devido a demanda de crianças aos centros de saúde escolhidos, ser maior na. faixa etária de 0 à 4 anos, a população estudada ficou restrita a essa última faixa.

Os periodos de execução foram: dois meses em 1974 e 2 meses em 1975 correspondente ao período que os alunos tinham estágio no campo.

Para a consulta de enfermagem às crianças, utilizamos os seguintes instrumentos:

* Professor Assistente Doutor da Disciplina Enfermagem de Saúde Pública da Escola de Enfermagem da USP.

Trabalho feito em colaboração com os docentes da referida disciplina: Malvina de Oliveira Ramos Netto, Eloisa Aparecida Guedes, Emiko Yoshikawa Egry, Rosa Maria G. S. da Fonseca, Vilma M. de Queiroz, Doralice S.F. Andrade e alunos da Habilitaçāo em Enfermagem de Saúde Pública de 1974 e 1975. 
NOGUEIRA, M.J.C. - Uma experiência com consultas de enfermagem para crianças.

Rev. Bras. Enf.; DF, 30 : 29.1-306, 1977.

2.1 ficha para coleta de dados, registro de orientaçōes transmitidas e avaliação dos resultados obtidos. Esta ficha, inicialmente, deveria ser mais resumida e pretendia-se utilizar os dados existentes nos prontuários das crianças matriculadas nos centros de saúde escolhidos. Como na época, entretanto, ambos os serviços nāo dispunham de impresso especifico para o registro de dados sóciosanitários das crianças, elaboramos um (modelo em anexo) para o nosso trabalho;

2.2 livro para agendar as consultas, no qual eram registrados nāo só os nomes das crianças a serem atendidas, mas 0 número da matrícula no centro de saúde, a data e hora da consulta;

2.3 talāo de encaminhamento onde era anotado o nome da criança, a atividade para a qual estava sendo encaminhada, a data e o horário, além do nome de quem havia encaminhado;

2.4 um fichário tipo "rotativo", com fichas indices, com o nome da criança, número de matrícula no centro de saúde e endereço completo. A finalidade desse fichário era a de poder controlar as crianças assistidas pela consulta $e$ planejar para ela e sua familia, as atividades subsequentes. Para isso, as fichas de cada criança eram marcadas com "clips" coloridos e cada cor indicava a atividade prioritária subsequente a ser realizada para aquela criança ou sua familia;

2.5 manual de instruçōes com normas do serviço além daquelas planejadas para o trabalho dos alunos. Resumidamente, esse manual continha o seguinte: objetivos da assistência, atividades necassárias, fluxograma do atendimento, normas para o atendimento e modelos dos impressos a serem utilizados.

Antes de iniciar o estudo, um dos docentes responsáveis pelos alunos, entrou em contacto com o médico-chefe das unidades sanitárias escolhidas, além dos médicos pediatras, enfermeiras o obitetrizes que trabalhavam nos mermos, a fím de combinar a execução do estudo. Em seguida, permaneceu aproximadamente cerca de duas semanas testando os instrumentos, fazendo as correçōes necessárias e agendando consultas. Após isso, iniciou o trabalho que consistiu em demonstrar uma consulta a dois ou três alunos e, em seguida, esses mesmos alunos executarem pelo menos uma.

$\mathrm{Na}$ primeira consulta, como havia necessidade de ser preenchida a ficha da criança com todos os dados sócio-sanitários da família, importantes para a avaliaçāo e assistência de enfermagem, gastava-se em média, uma hora e para as subseqüentes, cerca de trinta minutos.

A consulta de enfermagem foi definida para o estudo em questāo, como sendo a atividade a ser desempenhada, no serviço, pela enfermeira de saúde pública (docente e alunos), com a finalidade de supervisionar a saúde de crianças supostamente sadias matriculadas no serviço.

As atividades anteriores à consulta de enfermagem foram: encaminhamentos, matricula e inscriçāo.

Os encaminhamentos constavam de uma orientaçāo à māe da criança a respeito dos objetivos e necessidades das consultas, além do fornecimento do talāo de encaminhamentos já descrito anteriormente.

As crianças eram encaminhadas pelas enfermeiras e obstetrizes do serviço, por outros docentes e pelos próprios alunos que estagiavam em outros serviços do centro de saúde tais como: vacinaçāo, pré-natal e visitaçāo domiciliária.

O consultório utilizado para as consultas de enfermagem foi o mesmo utilizado pelo médico só que em horários diferentes e a consulta de enfermagem à criança teve, esquematicamente, as seguintes fases ou açōes: entrevista para coleta de dados, exame físico sumário, 
NOGUEIRA, M.J.C. - Uma experiência com consultas de enfermagem para crianças.

Rev. Bras. Enf.; DF, 30 : 294-306, 1977.

diagnóstico de enfermagem, registro de dados, encaminhamentos e prestação de cuidados e/ou orientaçōes.

$\mathrm{Na}$ execução da entrevista para a coleta de dados era levado em consideração o seguinte: a mãe e a criança eram colocadas confortavelmente sentadas e para as crianças que já seguravam objetos era dado um brinquedo para se distraírem enquanto a mãe prestava informaçōes. Antes de iniciar a entrevista. a mãe recebia uma orientação sobre os objetivos das perguntas que iriam ser feitas e sobre o sigilo que se faria dos dados registrados.

A entrevista coletava dados sócio-sanitários importantes sobre a criança e seu ambiente familiar e sobre sinais ou sintomas gerais de mal funcionamento de seus aparelhos ou sistemas. Resumidamente, os dados eram da seguinte natureza: identificação da criança e dos responsáveis, motivas que levaram à consulta de enfermagem, dados sócio-sanitários da familia e da habitação, condiçōes de saúde pregressa e atual da criança e dos familiares, hábitos de vida física, afetiva e social da criança na familia e aspectos gerais do desenvolvimento psico-motor.

Em seguida, era explicado à māe, os objetivos do exame físico sumário, procedendo-se imediatamente ao mesmo qus constava resumidamente, em ordem sequencial, de: medida de temperatura axilar, do peso e da altura, observação da aparência geral da criança e observação de: vestuário, pele, couro cabeludo e cabelos, ossos do crâneo, mucosas, pescoço, tronco, membros, genitais e cavidade oral.

Enquanto se fazia a entrevista e o exame físico sumário, observa-se o comportamento da mãe e da criança inclusive uma em relação à outra e, posteriormente, anotava-se o que chamasse mais a atenção.
Tanto a entrevista, como o exame fisico sumário, seguia um roteiro que era a própria ficha da criança e que possuia espaços suficientes para registrar cada tipo de dado.

$O$ diagnóstico de enfermagem significava, após a coleta de dados, concluir o seguinte: o que fazer para a criança e/ou o que orientar a mãe para fazer por ela. Após isso, procedia-se à prestação de cuidados necessários, como por exemplo um curativo, sempre seguidos de orientação de como fazer.

As outras orientaçōes eram dadas verbalmente e, quando a mãe era alfabetizada ou tinha alguém que lesse para ela em casa, no caso das analfabetas. também por escrito. Para essas orientações utilizava-se, também, de material audiovisual elaborado pelos alunos ou já existentes no próprio centro de saúde.

Os encaminhamentos após as orientações, em geral, eram feitos de acordo com os problemas e necessidades de cada caso e geralmente a outros profissionais do próprio centro de saúde (médicos, assistente social), a profissionais de outros serviços (psicólogos, odontólogos, assistentes sociais), a serviços do próprio centro de saúde (vacinação, testes) ou da comunidade (creches, escolas, serviço social) ou para nova consulta de enfermagem ou visita domiciliária.

Algumas vezes, além das crianças, quando havis necessidade, os pais também eram encaminhados aos mesmos tipos de profissionais e serviços.

Nas consultas subsequentes, antes de se iniciar a entrevista, eram estudadas a; anotaçōes da última consulta de enfermagem, da consulta médica e visitas dcmiciliárias realizadas. Para esta consulta, utilizava-se para registro de dados, de "fichas de continuação". Para os dados referentes às perguntas feitas à mãe, tanto da primeira como das outras consultas, era anotado à medida em que 
NOGUEIRA, M.J.C. - Uma experiência com consultas de enfermagem para crianças.

Rev. Bras. Enf.; DF, 30 : 294-306, 1977.

as respostas eram dadas mas, as orientaçōes, o exame físico e o preenchimento do resumo avaliativo da assistência de enfermagem, somente após a saída da mãe com a criança.

Além do registro dos dados na ficha da criança, a atividade era anotada, juntamente com a data, no cartão índice do f:chário "rotativo" já descrito.

As fichas utilizadas para a consulta de enfermagem, em um dos centros de saúde, ficavam dentro de um envelope do fichário central, anexadas à ficha de consulta médica pediátrica. No outro centro de saúde, por estar o fichário niuito desorganizado, as utilizadas para a consulta de enfermagem não ficaram anexadas embora se considerasse que seria muito proveitoso para o serviço.

\section{RESULTADOS}

3.1 Características sócio-econômicas e sanitárias.

As crianças atendidas perfaziam um total de 46, sendo 25 meninos e 21 meninas e a faixa etária predominante $(67,4 \%)$ pertencia a menores de um ano.

O meio familiar destas crianças, tinham as seguintes caracteristicas:

- os pais ganhavam, em média, 2,3 salários minimos;

- as famílias eram constituídas por uma média de 2,4 adultos (individuos maiores de 12 anos) e 2,4 crianças;

- a grande maioria $(74,7 \%)$ das familias tinham direito à previdência social (INPS) ou a outro tipo de recurso de saúde na comunidade embora nem todos os utilizassem;

- a maioria $(\mathbf{7 4 , 0 \%})$ das famílias pagava aluguel ou morava em casas cedidas por parentes ou conhecidos $\mathrm{em}$ bora para a maioria $(69,0 \%)$ a habitação fosse unifamiliar;

- a média de pessoas por cômodo em que se poderia dormir (quarto e sala), era de 2,9 e apenas $34,8 \%$ das fami- lias tinha rede de esgoto e $28,3 \%$ rede de abastecimento de água, embora para a maioria $(91.3 \%)$ o lixo fosse coletado pelo serviço público;

3.2 Principais problemas de saúde identificados por meio da entrevista com as mães.

\subsubsection{Alimentação e hidratação.}

Com relação a esses aspectos, os principais problemas foram:

- para metade das crianças, o desmame havia sido precoce e para quase metade $(41,7 \%)$ das menores de um ano, o aleitamento artificial era inadequado pelo seguinte: havia hiperdiluição do leite, para $42,1 \%$, hiperconcentração para $35,7 \%$ ou o leite não era o indicado para a idade para outras $(22,2 \%)$;

- para algumas crianças $(26,0 \%)$ a higiene do seios das mães ou das mamadeiras, era inadequada;

- somente $10,0 \%$ das crianças que mamavam no seio ou recebiam mamadeiras, o horário e a técnica de amamentação estavam adequados;

- a ingestão de outros alimentos (frutas, legumes, hortaliças, ovos, crrne, etc.) pelas crianças que estavam em idade de recebê-los, era precáría pois somente $31,7 \%$ o faziam;

-- quanto à hidratação, cerca de $30,0 \%$ das crianças, não recebiam líquidos (água ou chá) em quantidade suficlente;

\subsubsection{Asseio corporal.}

Os principais problemas de asseio corporal, foram: algumas mães $(8,7 \%)$ não davam banho diário nas crianças informando que não o faziam principalmente "quando o tempo não estava bom" e os cabelos e o couro cabeludo não eram lavados diariamente por $21,7 \%$, também pelos mesmos motivos.

Quanto ao perineo e genitais, a higiene não era boa para $388 \%$ das crianças, pois as mães só limpavam bem essa região 
NOGUEIRA, M.J.C. - Uma experiência com consultas de enfermagem para crianças. Rev. Bras. Enf.; DF, 30 : 294-306, 1977.

durante o banho e não após as evacuações ou micçōes.

Com relação às crianças maiores, quasc a maioria não lavava as mãos antes das refeições ou após o uso do sanitário e nenhuma escovava os dentes regularmente.

3.2.3 Funcionamento dos órgãos e aparelhos.

Os principais problemas relatados pelas mães, referentes ao funcionamento dos órgãos e aparelhos, foram:

- com relação às vias aéreas superiores $(33,3 \%)$ : bronquite, amigdalite, asma, máu hálito, moniliase. resfriado frequente, coriza, espirros repetidos e obstrução nasal;

- com relação ao cardio-respiratório $(16,7 \%)$ : "falta de ar" ao esforço, "chiado no peito", tosse frequente e cianose após a mamada;

- com relação ao gastro-intestinal $(11,1 \%)$ : cólicas e constipação intestinal;

- com relação ao sistema nervoso e psiquismo $(11,1 \%)$ : "nervosismo" choro freqüente, perda de fôlego, teimosia e "birras quando as vontades não eram satisfeitas";

- com relação ao geral, a inapetência fol o principal $(5,6 \%)$ e quanto a outros órgãos: secreção nos olhos $(5,6 \%)$, dor e secreção purulenta nos ouvidas $(1,3 \%)$, não se manter em pé sozinho $(1,3 \%)$, dentes cariados $(1,3 \%)$, febre freqüente $(1,3 \%)$, anemia $(1,3 \%)$, alergia a medicamentos $(1,3 \%)$, sífilis tratada $(1,0 \%)$ e vermes $(1,3 \%)$, foram os principais.

3.2.4 Sono, repouso, exercícios, vida ao ar livre e recreação.

Com relação a esses aspectos, os maiores problemas foram:

- $36,7 \%$ das crianças não dormiam bem e as causas eram: o número de horas não era suficiente, o sono era agitado, algumas rangiam os dentes, gemiam ou choravam à noite;
- $17,4 \%$ não se movimentava ou vivia ao ar livre de modo adequado e, principalmente, não tomava sol;

- 32,4\% não tinha recreação adequada e os motivos eram: os brinquedos não eram para a idade, só brincava nos feriados ou a mãe tinha medo de que a criança se machucasse.

3.2.5 Vida afetiva e social.

Com relação à vida afetiva e social, foram encontrados problemas em $45,6 \%$ das crianças atendidas. Esses problemas foram os seguintes: algumas crianças viviam só com as mães porque os pais tinham abandonado a família (23,8\%), outras $(23,8 \%)$ sou nascimento não tinha sido planejado, outras $(14,2 \%)$, as mães carregavam ao colo sempre que choravam e outras $(9,9 \%)$, faziam todas as vontades da criança.

3.2.6 Desenvolvimento psicomotor.

Das 46 māes das crianças atendidas, cerca de $39,0 \%$ não sabiam informar sobre a evolução do desenvolvimento psicomotor de seus filhos e das que informaram, foi encuntrada apenas uma crianca que não apresentava o desenvolvimento de acordo com o padrão para a idade.

3.2.7 Vacinações e controle médico.

Quanto às vacinaçōes de rotina, apenas $43,0 \%$ estava com o esquema em dia. Algumas mães $(10,0 \%)$ não sabiam informar a respeito da vacinação de seus filhos e também não tinham nenhum documento comprovante de vacinas.

Quanto ao controle médico, $69,4 \%$ das maiores de um mês, iam à consulta somente quando a mãe as considerava doentes. As restantes, iam somente quando tinham dúvidas a respeito do esquema alimentar ou para ganhar leite da unidade sanitária.

3.3 Principais problemas de saúde identificados por meio do exame físico sumário.

Ao exame físico sumário, foram constatados alguns problemas referentes aos 
NOGUEIRA, M.J.C. - Uma experiencia com consultas de enfermagem para crianças.

Rev. Bras. Enf.; DF, $30: 294-306,1977$.

genitais e períneo $(29,3 \%)$, pescoço, tronco e membros $(16,5 \%)$, pele $(14,2 \%)$, peso e altura $(13,2 \%)$, couro cabeludo e cabelos $(9,7 \%)$, aparência geral $(5,2 \%)$, cavidade oral $(4,5 \%)$, mucosas $(4,5 \%)$, vestuário $(2,2 \%)$ e cabeça $(0,75 \%)$.

Os principais problemas referentes aos genitais e períneo foram, em ordem decrescente: uso de talco em excesso, fimose, assadura e sujidades. Com relação à regiāo do pescoço, tronco e membros, foram: gânglios palpáveis, cicatriz umbilical protuberante ou hérnia umbilical, abdomem distendido, turgor frouxo, uso de faixa abdominal apertada, tumefação mamária e ferimento. Quanto à pele, lesōes tipo alérgicas ou suspeitas de escabiose, assaduras, palidez e quanto ao peso e altura, o maior problema, foi ambos abaixo do padrão. Com relação ao couro cabeludo e cabelos, o maior problema foi dermatite seborreica e segundo, a falta de asseio. Outros problemas foram: criança irritada ao exame físico, amigdalas hiperemiadas e aumentadas, mucosas descoradas, vestuário nāo de acordo com a temperatura ambiente e uma criança com suspeita de otite.

3.4 Freqüência dos problemas que precisavam de correção.

Os problemas que precisavam de correção foram, porcentualmente. em ordem decrescente, os referentes a: alimentação $(16,6 \%)$, condiçōes sócio-econômicas, principalmente as relacionadas com a habitação $(15,5 \%)$, imunizaçōes $(9,1 \%)$, controle médico $(9,1 \%)$, asseio corporal $(8,6 \%)$, funcionamento dos aparelhos $(8,6 \%)$, recreação $(6,3 \%)$, hidratação $(6,0 \%)$, sono $(3,6 \%)$, controle odontológico $(3,4 \%)$, exercícios e vida ao ar livre $(2,1 \%)$ e desenvolvimento psico-motor $(1,2 \%)$.

3.5 Tipo de cuidado de enfermagem prestado.

As orientaçōes dadas às mães das crianças foram principalmente sobre: asseio corporal e de utensílios $(31,0 \%)$, ali- mentação e hidratação $(27,59 \%)$, vida ao ar livre, vestuário, banho de sol, recreação, estímulo ao desenvolvimento psicomotor, sono e exercícios $(16,5 \%)$, vacinação e teste tuberculínico $(8,6 \%)$, higiene da habitação $(6,5 \%)$, utilização de profissionais e serviços de saúde e outros recursos sociais da comunidade $(5,4 \%)$, uso de medicamentos prescritos pelo médico $(2,7 \%)$ e cuidados com a fimose $(1,5 \%)$.

Os encaminhamentos feitos não só para as crianças, mas também para seus pais e irmãos, foram para: vacinação e teste tuberculínico $(33,8 \%)$, consulta médica $(29,0 \%)$, INPS $(9,7 \%)$, outros serviços do centro de saúde tais como o de pré-natal, o odontológico e lactário $(8,2 \%)$, hospital da comunidade $(6,5 \%)$, serviço social do centro de saúde ou da comunidade $(3,2 \%)$, BENFAM $(3,2 \%)$ e MOBRAL $(3,2 \%)$.

Quanto a tratamentos, foram feitos apenas para $13,0 \%$ das crianças e se restringiram à colocação de esparadrapo para redução de hérnia umbilical e curativo umbilical.

Não foi possivel verificar quais os problemas que foram corrigidos pois, devido ao pouco tempo de permanência dos alunos e docentes nos serviços a saúde onde foi realizado o estudo, nàu foram realizadas consultas subseqüentes para todas as crianças que receberam as primeiras consultas de enfermagem.

\section{CONCLUSOES}

A consulta de enfermagem para o grupo de crianças alvo do estudo, foi valiosa não só porque identificou problemas sócio-sanitários das mesmas, mas também, porque procurou assistir a esses problemas de forma racional, utilizando os recursos disponíveis no serviço e na comunidade. Quanto aos alunos de enfermagem, consideramos valiosa a exporiência para a sua futura vida profissional. 


\section{ANEXO \\ UNIVERSIDADE DE SÃO PAULO \\ ESCOLA DE ENFERMAGEM}

\section{DISCIPLINA: Enfermagem de Saúde Pública II}

\section{FICHA DE ASSISTENCIA DE ENFERMAGEM \\ (Saúde da criança)}

\section{HISTORICO}

\subsection{IDENTIFICAÇAOO}

Nome

N. ${ }^{\circ}$ de matrícula

Data de nascimento

Sexo

Data de abertura da ficha

Fillaçāo: pai

māe

Enderêço

1.2 MOTIVO DA CONSULTA

1.3 DADOS SÓCIO-SANITARIOS DA FAMILIA

1.3.1 condições sócio-econômicas:

- n. ${ }^{\circ}$ de pessoas na familia: adultos ...... crianças ......

- renda familiar

- orçamento familiar: alimentaçāo (\$) .... habitaçāo (\$)

- instruçāo: paí ............... māe

- ocupaçāo: paí .............. māe

- previdência social e outros recursos

1.3.2 habitaçāo: própria ( ) alugada ( ) cedida ( ) outras .....

- unifamiliar ( ) coletiva ( ) n.o de familias

- tipo de construçāo

- relaçāo pessoa/cômodo

- relação pessoa/cama

- procedência da água

- destino do lixo

- destino dos dejetos 
NOGUEIRA, M.J.C. - Uma experiência com consultas de enfermagem para crianças. Rev. Bras. Enf.; DF, $30: 294-306,1977$.

- outras características

\subsection{CONDIÇOES DE SAÚDE DA CRIANÇA}

1.4.1 gestação: pré-natal ( ) local ........ medicamentos tempo de gestação ............. intercorrências

1.4.2 parto: tipo local assistência ............ peso ao nascer ...... altura ..... chorou logo ( ) cianose ( ) reanimação ( ) intercorrências neo-natais

1.4.3 desenvolvimento: sustentou a cabeça sentou-se $10^{\circ}$ dente controle de esfincteres

1.4.4 antecedentes mórbidos:

Data

Doença Local

Atendimento

Conduta

1.4.5 antecedentes familiares $e$ hereditários:

\begin{tabular}{|c|c|c|c|c|}
\hline & Tipo & Observações & Tipo & Observações \\
\hline & $\begin{array}{l}\text { Neoplasias } \\
\text { D. cardio-vasc. } \\
\text { Diabetes } \\
\text { Sifilis } \\
\text { Hanseniase }\end{array}$ & & $\begin{array}{l}\text { Alcoolismo } \\
\text { Alergia } \\
\text { Tuberculose } \\
\text { D. Mentais } \\
\text { Outras: }\end{array}$ & \\
\hline 1.4 .6 & imunizações: & & & \\
\hline & Tipo & Data a & eplicação & Reações \\
\hline
\end{tabular}

B.C.G.

Triplice (C.D.T.)

Antivariblica

Sarampo

Dupla (D.T.) 
NOGUEIRA, M.J.C. - Uma experiência com consultas de enfermagem para crianças. Rev. Bras. Enf.; DF, 30 : 294-306, 1977.

Anti-tetânica

Sabin

Soro

Outras

Testes:

Mantoux

Schick

Outros

1.4.7 Situação alimentar: alimentação natural até intercorrências alimentares

- alimentação atual:

- aleitamento natural ( ) limpeza dos seios n. ${ }^{\circ}$ de mamadas/dia ............. interva 0 técnica de adminstração

- aleitamento artificial ( ) fórmula láctea desinfecção da mamadeira técnica de administração outras características

- geral ( ) leite e derivados ( ) qt/dia carnes e ovos ( ) qt/dia hortaliças ( ) qt/dia frutas ( ) qt/dia outros

- hidratação:

- vitaminas sintéticas:

1.4.8 Funcionamento dos aparelhos:

- geral (peso, atividade, apetite, etc.)

- intercorrências (febre, medicação, etc.)

- olhos (visão, secreçōes, lacrimejamento, etc.)

- ouvidos (audição, dor, secreções, etc.)

- dentes (n. ${ }^{\circ}$, estado de conservação, dor, etc.)

- garganta (infecçōes repetidas, mau hálito, etc.)

- infecções das vias aéreas superiores (coriza, freqüência, etc.)

- cardio-respiratório (tosse, "chiado", cianose, falta de ar, freqüência, etc.)

- gastro-intestinal (cor, jato, volume, freqüência, corrimento, prurido, menarca, etc.) 
NOGUEIRA, M.J.C. - Uma experiência com consultas de enfermagem para orianças. Rev. Bras. Enf.; DF, $30: 294-306,1977$.

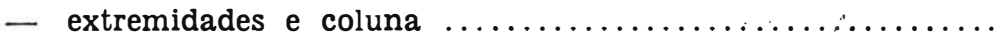
(edemas, paralisias, seqüelas, reumatismo, etc.)

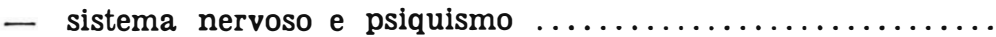
(convulsōes, desmaios, perda de folego, distúrbios de comportamento, temperamento, etc.)

- observaçōes:

1.4.9 Asseio corporal:

(couro cabeludo, banho, genitais. dentes, mãos, etc.)

1.4.10 Sono:

(n. ${ }^{\circ}$ horas, distúrbios, tipo de berço, etc.)

1.4.11 Exercicios:

(p/idade, freqüência, etc.)

1.4.12 Recreação:

( $p /$ idade, freqüência, etc.)

1.4.13 Vida afetiva e social: (relacionamento com os pais, amigos, métodos disciplinares, etc.)

1.4.14 Vida escolar:

(aproveitamento, relacionamento, etc.)

1.4.15 Controle médico periódico:

(periodicidade, causas, local de atendimento, etc.)

1.4.16 Controle odontológico:

(periodicidade, causas, local de atendimento, etc.)

Jbservaçōes: 
NOGUEIRA, M.J.C. - Uma experiência com consultas de enfermagem para crianças. Rev. Bras. Enf.; DF, 30 : 294-306, 1977.

1.5 RESUMO DO DESENVOLVIMENTO $(0-6$ anos $=$ pré-escolar $)$

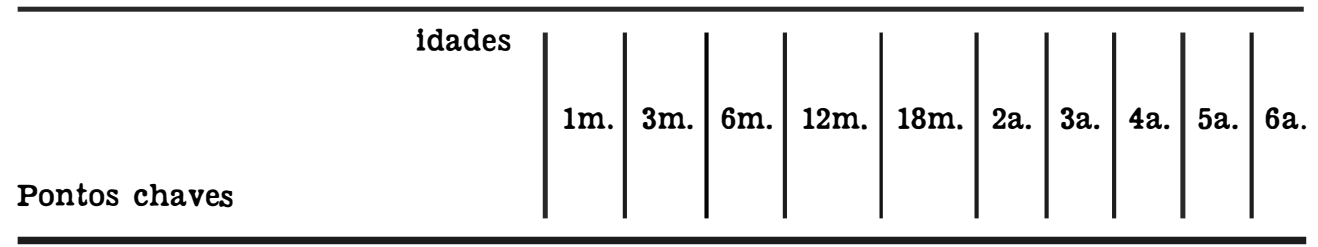

5.1 Dentição

- erupção

- troca

- molar permanente

5.2 Neuropsicomotor

- firma a cabeça
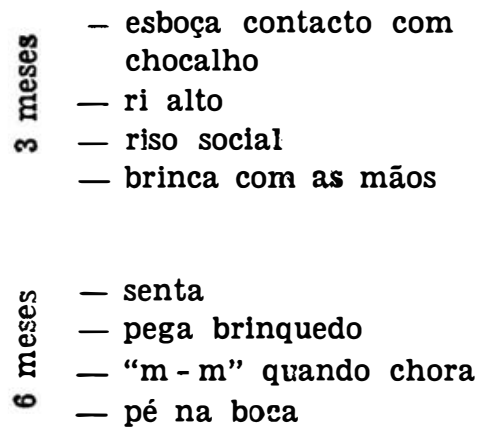

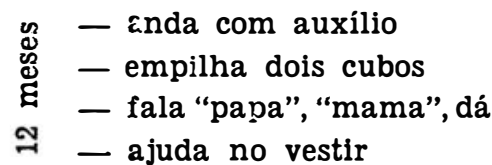

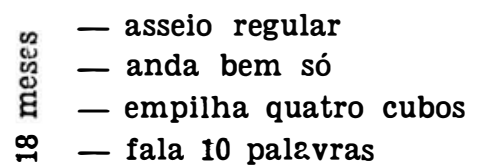

:

i - junta 2 - 3 palavras

- controle esfincteriano

- anda de triciclo

o - faz uma ponte com 3 cubos

m - forma oração

- come bem só 
NOGUEIRA, M.J.C. - Uma experiência com consultas de enfermagem para criançass. Rev. Bras. Enf.; DF, $30: 294-306,1 y^{\prime} i 7$.

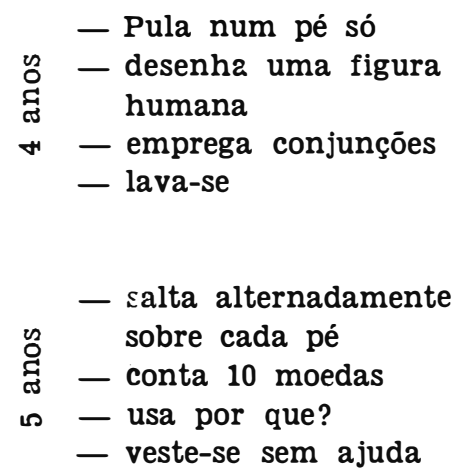

Observaçōes:

2. EXAME FISICO-SUMARIO

2.1 temp. PA Peso

(g) Altura $(\mathrm{cm})$

2.2 aparência geral

$$
\begin{aligned}
& \text { - bem disposto ( ) } \\
& \text { - calmo } \\
& \text { - tranquilo } \\
& \text { - outras características }
\end{aligned}
$$

indisposto ( )

agitado ( )

irritado ( )

2.3 vestuário: de acordo com a temp. ( ) Não de acordo ( ) Limpo ( ) Sujo ( )

2.4 pele: - limpa ( ) suja ( ) corada ( ) pálida ( ) ictérica ( )

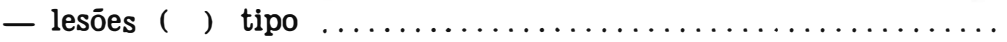

- outras características

2.5 couro cabeludo: - limpos ( ) sujos ( ) lesōes ( ) tipo

$$
\text { e cabelos - outras características }
$$

2.6 cabeça: - fontanela ausente ( ) presente ( ) depressāo normal ( ) - deprimida ( ) abaulada ( )

2.7 mucosas: - coradas ( ) descoradas ( ) lesōes ( ) tipo .......... - outras características

2.8 pescoço, tronco: - gânglio palpáveis ( ) não palpáveis ( ) turgor ( ) firme ( )

e membros - frouxo ( ) abdomem normal ( ) distendido ( ) encovado ( )

- outras características

2.9 genitais: - limpos ( ) sujos ( ) outras caracteristicas 
NOGUEIRA, M.J.C. - Uma experiência com consultas de enfermagem para crianças. Rev. Bras. Enf.; DF, $30: 294-306,1971$.

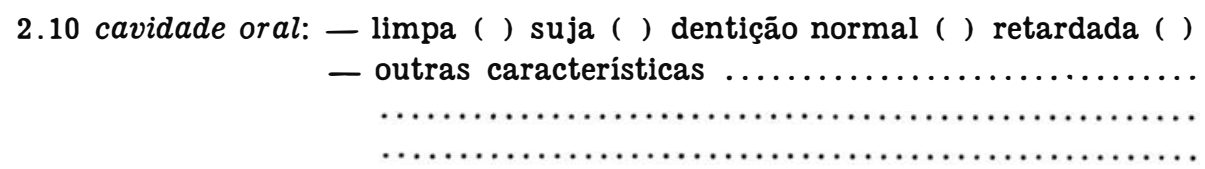

3. CONCLUSOES E ORIENTAÇOES DA $1 .^{a}$ CONSULTA

4. FICHA DE CONTINUAÇAO

Nome:

Data:

Tipo de

Assistência

N. ${ }^{\circ}$ de matrícula:

Assistência Anotaçōes Assinatura

5. RESUMO AVALIATIVO DA ASSISTENCIA DE ENFERMAGEM

\begin{tabular}{l|l|l|l}
\hline CÓDIGO: & satisfatório $=0$ & $\begin{array}{l}\text { precisando } \\
\text { correção }\end{array}=\mathbf{x}$ & corrigido $=00$ \\
\hline
\end{tabular}

1. Cond. sócio-econômicas

sanitárias da família

- habitação

- recursos da comunidade

- orçamento e renda

2. Alimentação

3. Hidratação

4. Funcionamento dos apa-

relhos

- gastro-intestinal

- órgãos dos sentidos

- dentes

- cárdio-respiratório

- s. nervoso e psiq.

- outros

5. Desenvolvimento psicomotor

6. Imunizaçōes

7. Asseio corporal

8. Sono

9. Exercícios

10. Recreação

11. Vida afetiva e social

12. Vida escolar

13. Controle médico

14. Controle odontológico

15. Controle de enfermagem 